\title{
Validation of Brief Affective Neuroscience Personality Scales in normal populations
}

\author{
Walidacja skali Brief Affective Neuroscience Personality Scales u osób zdrowych
}

\author{
Sohrab Amiri², Esfandiar Azad-Marzabadi² \\ ${ }^{1}$ Urmia University, Faculty of Literature and Humanities, Department of psychology, Urmia, Iran \\ ${ }^{2}$ Baqiyatallah University of Medical Sciences, Behavioural Sciences Research Centre, Tehran, Iran \\ Neuropsychiatria i Neuropsychologia 2017; 12, 3: 95-100 \\ Address for correspondence: \\ Ph.D. Sohrab Amiri \\ Urmia University \\ Urmia, Iran \\ e-mail: amirysohrab@yahoo.com
}

\begin{abstract}
Aim of the study: To evaluate the psychometric properties of Brief Affective Neuroscience Personality Scales (BANPS). Material and methods: For this purpose, 326 normal participants were selected, then the Brief Affective Neuroscience Personality Scales: Negative and Positive Affect Scale (NAPAS) and the Emotion Awareness Questionnaire were distributed among them to respond. The reliability of the Questionnaire was evaluated by Cronbach's $\alpha$, retest, and split-half coefficient, and then the criterion validity with other questionnaires was evaluated to determine the psychometric properties of the BANPS. The factor structure was assessed via confirmatory factor analysis.

Results: The results of the factor analysis indicated that BANPS has six factors, and checking the reliability by using Cronbach's $\alpha$, retest and split-half coefficient reflects the stability of the scale and the criterion validity of the BANPS with other questionnaires showed desirable discriminant and convergent validity.

Conclusions: Overall, the findings indicated that BANPS has good psychometric properties in normal samples, and the scale can be used in studies in normal samples.
\end{abstract}

Key words: affective neuroscience, factor analysis, reliability, validity.

\section{Introduction}

There are individual differences in temperament and mood that reflect emotional differences (Rothbart, Ahadi, and Evans 2000). It is believed that these emotional systems are shaped by evolution (Panksepp 2012). Although everyone has elemental knowledge of emotion, trying to define emotions is difficult; emotion refers to a wide variety of responses that can range from mild to severe, from positive to negative, from general to private, from short to long term, primary (primary emotional response), to secondary (converting a reaction emotion to another emotional response) (Kring and Sloan 2010).

Based on the functional perspective, emotions include adaptive responses to life problems and opportunities, in general, contemporary theories of emotion emphasise the role and importance of emotions in providing physiological, behavioural, and motor responses, facilitating decision making and promoting memory for important incidents and interpersonal interactions (Gross and Thompson 2007).

Individuals show different emotional responses and vary in the rate of being susceptible to positive and negative excitement (Watson, Clarke, and Hawkins 1994), which reflects individual differences in the cognitive processing of received information. Given what has been said, emotions play an important role in different aspects of life, such as adaptation to life changes and stressful events. The results of the research show that emotions at any moment affect the attention (Vulliomir 2005), memory, and physiological responses. Emotional disturbance is the main factor of many dimensions of psychopathology (Kring 2008). Accordingly, negative emotions or the unpleasant consequences of such emotions have been reported in a range of different psychopathology problems (Surawy, Hackmann, Hawton, and Sharpe 1995; Ali et al. 2000), somatisation disorders (Woolfolk and Allen 2007), eating disorders (Corstorphine 
2006), depression (Cramer, Gallant, and Langlois 2005), and Post Traumatic Stress Disorder (PTSD) (Ehlers and Clark 2000).

Over the past decades, an explosion of interest in emotional processes in psychology has been created, and as a result, researchers have focused more on the emotional dimension. Given that individual differences in initial emotions have an important impact on personality. An important step in the test of this hypothesis is the existence of desirable and valid scales. Accordingly, various scales have grown to measure emotional dimensions; one of the known scales in this area is the Brief Affective Neuroscience Personality Scales (BANPS; Davis, Panksepp, and Normansell 2003). A short version of this scale has been shaped by Barrett, Robins, and Janata (2013). This scale involves six major emotions: Play, Anger, Seek, Care, Fear, and Sadness. This study aimed to validate a measure of brief BANPS and examined the internal reliability and validity of the scale in the normal population.

\section{Material and methods}

\section{Procedures}

The participants comprised 326 samples. In this way, the research data were collected from the samplesduring one month. Of the total participants, 248 were undergraduates $(76 / 1 \%)$ and 78 had master's degrees and higher (23.9\%).

In order to collect data, the researcher had a meeting with the participants and gave the necessary explanations and then distributed the BANPS, Negative and Positive Affect Scale (NAPAS), and Emotion Awareness Questionnaire among them.

\section{Measures}

Brief Affective Neuroscience Personality Scales: This scale is designed to measure the six main dimensions of behavioural traits associated with the brain-nervous system (play, seek, care, fear, anger, and sadness) and is scored based on the five-point Likert scale. The neurobiological system underlying this scale is an animal model (Barrett, Robins, and Janata 2013).

In order to provide the Persian version of the BANPS, the researcher and two experts in English language translated the questionnaire into fluent Persian and then the translated text was edited. At the next step, the translated version was turned into English language again by the researcher and the two language experts, and after that the two versions were reconciled. To examine the face validity, the questionnaire was then given to two psychologists. After reconciling the two translated and main versions and eliminating the mistakes, the questionnaire was conducted on 40 university students who were similar to the study final population, and after receiving essential feedback on the items' content and fixing the raised weaknesses, the final version of the questionnaire was prepared for use.

Emotion Awareness Questionnaire: This questionnaire is used to measure emotional awareness dimensions and has 30 items and six sub-scales and is scored based on the three-level Likert scale. The Cronbach's $\alpha$ coefficients for the subscales of this questionnaire $\alpha=64$ to $\alpha=68$ were obtained (Rieffe et al. 2007).

Negative and Positive Affect Scale: This questionnaire was designed to measure the positive and negative affect dimensions and includes 12 items and two subscales of positive affect and negative affect (Mroczek and Kolarz 1998). The questionnaire is scored on a five-point Likert scale from 1 to 5, Cronbach's $\alpha$ coefficients for both positive and negative subscales was obtained $\alpha=91$ and $\alpha=84$, respectively (Joshanloo 2017).

\section{Ethical provisions}

All procedures performed in studies involving human participants were in accordance with the ethical standards of the institutional and/or national research committee and with the 1964 Helsinki declaration and its later amendments, or comparable ethical standards. The Institutional Review Board of Baqiyatallah University approved this study. Informed consent was obtained from all individual participants included in the study.

\section{Data analytic strategy}

SPSS version 22 (SPSS IBM, New York) and LISREL software (Jöreskog and Sörbom 2006) were used to perform statistical analyses. Bivariate correlations, Cronbach's $\alpha$, split-half and test-retest coefficients, and confirmatory factor analysis were assessed to examine the convergent validity, internal consistency, and factor structure of BANPS.

\section{Results}

\section{Validity}

The BANPS validity was examined by two means; the criterion validity (conducted simultaneously with the NAPAS and Emotion Awareness 
Questionnaire) and the correlation between subscales. The results are shown in Table 1.

The pattern of correlation coefficients between the subscales in Table 1 shows there is good internal consistency between the subscales. The pattern of correlation coefficients between the subscales with NAPAS and Emotion Awareness Questionnaire indicates the concurrent criterion validity of BANPS.

\section{Reliability}

To investigate the reliability of the BANPS, Cronbach's $\alpha$, split-half, and test-retest coefficients were calculated. The 33-question scale's Cronbach's coefficient was 0.79 , which showed that the scale has a good internal consistency. The split-half coefficient also indicated the scale and its subscale's high reliability. Forty partic- ipants answered the questionnaire's questions again two weeks later to calculate the retest coefficient, and the obtained scores' correlation coefficients were calculated after conduction of the two tests. The results of the Cronbach's $\alpha$, the split-half, and test-retest coefficients are presented in Table 2.

Table 2 shows that Cronbach's $\alpha$ coefficients were satisfactory and the data of all the testretest and split-half s coefficients were significant. Therefore, it can be concluded that the BANPS has good internal consistency

\section{Factor analysis}

Exploratory factor analysis and confirmatory factor analysis were used to study the structure of the questions. The exploratory factor analysis was done using the principal component anal-

Table 1. Correlation coefficients between the subscales of Brief Affective Neuroscience Personality Scales with other tools

\begin{tabular}{|c|c|c|c|c|c|c|c|c|c|c|c|c|c|c|}
\hline Subscale & 1 & 2 & 3 & 4 & 5 & 6 & 7 & 8 & 9 & 10 & 11 & 12 & 13 & 14 \\
\hline Play & 1 & & & & & & & & & & & & & \\
\hline Anger & .10 & 1 & & & & & & & & & & & & \\
\hline Seek & $.38^{\star *}$ & $.22^{* *}$ & 1 & & & & & & & & & & & \\
\hline Care & $.64^{\star *}$ & -.02 & .06 & 1 & & & & & & & & & & \\
\hline Fear & $.27^{\star \star}$ & $.27^{\star \star}$ & -.01 & $.15^{\star \star}$ & 1 & & & & & & & & & \\
\hline Sadness & .07 & $.32^{\star *}$ & $.18^{\star *}$ & -.05 & $.39^{\star *}$ & 1 & & & & & & & & \\
\hline $\begin{array}{l}\text { Differentiating } \\
\text { emotions }\end{array}$ & $-.34^{* *}$ & $-.59^{* \star}$ & -.06 & $-.35^{\star *}$ & $-.38^{* *}$ & $-.27^{\star \star}$ & 1 & & & & & & & \\
\hline $\begin{array}{l}\text { Verbal sharing } \\
\text { of emotions }\end{array}$ & $0.22^{* *}$ & $-.29^{\star \star}$ & -.01 & $.27^{\star \star}$ & .01 & $-.26^{\star \star}$ & $.17^{\star *}$ & 1 & & & & & & \\
\hline $\begin{array}{l}\text { Not hiding } \\
\text { emotions }\end{array}$ & -.01 & $-.16^{\star \star}$ & $-.21^{\star \star}$ & $-.18^{\star \star}$ & .08 & -.05 & $.33^{* *}$ & $.12^{*}$ & 1 & & & & & \\
\hline $\begin{array}{l}\text { Bodily } \\
\text { awareness }\end{array}$ & $.19^{\star \star}$ & $-.33^{\star \star}$ & -.10 & $.38^{\star *}$ & $-.27^{\star \star}$ & $-.12^{\star}$ & $.30^{\star \star}$ & $.64^{\star \star}$ & $.21^{\star \star}$ & 1 & & & & \\
\hline $\begin{array}{l}\text { Attending } \\
\text { to others' } \\
\text { emotions }\end{array}$ & $-.15^{\star *}$ & - & - & $-.11^{\star}$ & $.23^{\star *}$ & -.04 & $-.20^{\star *}$ & $-.23^{\star \star}$ & .01 & $-.12^{*}$ & 1 & & & \\
\hline $\begin{array}{l}\text { Analyses } \\
\text { of emotions }\end{array}$ & $.32^{\star *}$ & $.23^{* *}$ & $.13^{*}$ & $.26^{\star *}$ & $.53^{\star *}$ & $.20^{\star *}$ & $-.48^{\star *}$ & .02 & $-.26^{\star \star}$ & $-.18^{\star *}$ & $.30^{\star *}$ & 1 & & \\
\hline Negative & -.03 & $.34^{\star *}$ & .10 & $.18^{\star *}$ & $.21^{\star *}$ & $.51^{\star *}$ & $-.57^{\star \star}$ & $-.17^{\star \star}$ & $-.41^{\star \star}$ & -.03 & $.11^{*}$ & $.41^{\star \star}$ & 1 & \\
\hline Positive & $.45^{\star \star}$ & -.03 & $.17^{\star \star}$ & -.03 & $.21^{\star \star}$ & $-.13^{\star}$ & .06 & $.13^{*}$ & $.36^{\star \star}$ & $-.13^{\star}$ & $-.28^{\star \star}$ & .03 & $-.53^{\star *}$ & 1 \\
\hline
\end{tabular}

Table 2. The mean, standard deviation, $\alpha$, and test-retest coefficients of the Brief Affective Neuroscience Personality Scale

\begin{tabular}{|c|c|c|c|c|}
\hline Subscale & Mean /SD & $\alpha$ Coefficient & Test-retest & Split-half coefficient \\
\hline Play & $19 / 70(4.50)$ & $0 / 81$ & $0 / 69^{* *}$ & $0 / 70$ \\
\hline Anger & $18 / 80(4 / 11)$ & $0 / 75$ & $0 / 71^{\star \star}$ & $0 / 53$ \\
\hline Seek & $17 / 70(3 / 22)$ & $0 / 75$ & $0 / 58^{\star *}$ & $0 / 47$ \\
\hline Care & $11 / 39(3 / 13)$ & $0 / 79$ & $0 / 72^{* \star}$ & $0 / 51$ \\
\hline Fear & $17 / 76(3 / 46)$ & 0/79 & $0 / 66^{\star *}$ & $0 / 55$ \\
\hline Sadness & $19 / 56(3 / 69)$ & $0 / 73$ & $0 / 70^{\star *}$ & $0 / 66$ \\
\hline
\end{tabular}


Table 3. The intersection rate of each question with the whole questionnaire, eigenvalue, and explanation percentage of each factor after orthogonal rotation based on principal component analysis Brief Affective Neuroscience Personality Scales model

\begin{tabular}{|c|c|c|c|c|c|c|c|c|}
\hline Subscale & Item & Factor load & subscale & Item & Factor load & subscale & Item & Factor load \\
\hline Play & $\begin{array}{c}1 \\
9 \\
13 \\
19 \\
22 \\
29\end{array}$ & $\begin{array}{l}0 / 548 \\
0 / 772 \\
0 / 856 \\
0 / 851 \\
0 / 555 \\
0 / 891\end{array}$ & Seek & $\begin{array}{c}3 \\
21 \\
25 \\
28 \\
31 \\
33\end{array}$ & $\begin{array}{l}0 / 750 \\
0 / 586 \\
0 / 935 \\
0 / 471 \\
0 / 456 \\
0 / 752\end{array}$ & Fear & $\begin{array}{c}6 \\
15 \\
17 \\
23 \\
30\end{array}$ & $\begin{array}{l}0 / 765 \\
0 / 750 \\
0 / 858 \\
0 / 493 \\
0 / 486\end{array}$ \\
\hline Eigenvalue & & $3 / 55$ & & $2 / 82$ & & & $2 / 79$ & \\
\hline $\begin{array}{l}\text { The variance's } \\
\text { explanation percentage }\end{array}$ & & $10 / 75$ & & $8 / 56$ & & & $8 / 47$ & \\
\hline Anger & $\begin{array}{c}2 \\
5 \\
11 \\
20 \\
24 \\
26\end{array}$ & $\begin{array}{l}0 / 814 \\
0 / 527 \\
0 / 640 \\
0 / 904 \\
0 / 869 \\
0 / 709\end{array}$ & Care & $\begin{array}{l}4 \\
14 \\
16 \\
27\end{array}$ & $\begin{array}{l}0 / 820 \\
0 / 471 \\
0 / 845 \\
0 / 647\end{array}$ & Sadness & $\begin{array}{c}7 \\
8 \\
10 \\
12 \\
18 \\
32\end{array}$ & $\begin{array}{l}0 / 713 \\
0 / 637 \\
0 / 592 \\
0 / 571 \\
0 / 684 \\
0 / 789\end{array}$ \\
\hline Eigenvalue & & $2 / 86$ & & $2 / 81$ & & & $2 / 70$ & \\
\hline $\begin{array}{l}\text { The variance's } \\
\text { explanation percentage }\end{array}$ & & $8 / 67$ & & $8 / 54$ & & & $8 / 19$ & \\
\hline
\end{tabular}

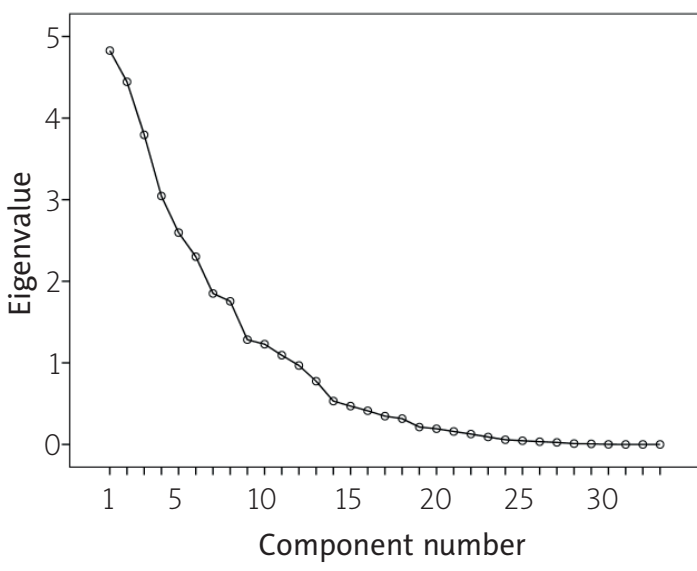

Fig. 1. The slope of the components (scree plot)

ysis, and orthogonal rotation was performed. The obtained value for Kaiser-Meyer-Olkin Measure of Sampling Adequacy (KMO) was 0.83 and Bartlett's Test of Sphericity $\left(\chi^{2}=458.681\right)$ showed that factor analysis is possible. The intersection rate of each question with the whole questionnaire, factor loading matrix, and eigenvalue and variance percentage explained by any factor are presented in Table 3.

The slope of the components' results (scree plot) in Figure 1 and the analysis of the principal components showed the existence of six components with value greater than 1 , which explained the $53 / 22$ percent of variance. Data in Table 4 indicate that extracted factor loads are higher than 0.40 and distribution of the items in factors corresponds with the questionnaire's theoretical basic structure. In order to investigate the fit of the six-factor structure of the BANPS, confirmatory factor analysis by maximum likelihood method and LISREL software were used (Jöreskog and Sörbom 2006).

The confirmatory factor analysis, using LISREL software, offered three levels of fit indices (Brown 2006; Schermelleh-Engel et al. 2003): (1) absolute fit indices such as $\chi^{2}$ index and Standardised Root Mean Square Residual (SRMR), (2) parsimony goodness-of-fit index such as Root Mean Square Error of Approximation (RMSEA), and (3) Comparative Fit Index (CFI). There is controversy over the precise cutting scores of fit indices (Brown 2006; Schermelleh-Engel et al. 2003; Hair et al. 2009; Hu and Bentler 1999; Tabachnick and Fidell 2007). The more the scores of Normed Fit Index (NFI), Relative Fit Index (RFI), and Goodness of Fit Index (GFI) are closer to 1, the more they indicate the pattern's more desired fit. In the present study, the most valid fit scores have been used in order to assess the model's fit. SRMR $<.08$ shows a desired fit and SRMR $<.10$ indicates an acceptable fit, and the model is failed when SRMR > .10 (Hu and Bentler 1999). The index with value of RMSEA $\leq .8$ shows the model is good, and when the RMSEA is between 0.10 and 0.08 , the model is acceptable. Eventually, $\mathrm{CFI} \geq .95$ states the good fit of the model (Hu and Bentler 1999). Since the $\chi^{2}$ statistic is sensitive to the sample size, to assess the overall fit of the model, the amount of $\chi^{2}$ is calculated along with the degree of freedom $\left(\chi^{2} / \mathrm{df}\right)$. $\chi^{2} / \mathrm{df}<2$ represents the model's good fit and when $\chi^{2} / \mathrm{df}$ is around 3 the model is acceptable. 
The amount of $\chi^{2} / \mathrm{df}$ was 2.71 , which is around 3, so the model's fit is acceptable. In addition to this, $\mathrm{SRMR}=.05$ showed that the six-factor model's fit is acceptable and the fit indices of $\mathrm{CFI}=.95, \mathrm{NFI}=.91, \mathrm{RFI}=.93, \mathrm{AGFI}=.92$, and RMSEA $=.04$ represent the model's acceptable fit.

\section{Conclusions}

The Brief Affective Neuroscience Personality Scale is widely known to personality researchers. However, less attention has been paid to the brief form of BANPS. Hence, the present study was done to evaluate and validate the BANPS in normal samples.

The BANPS's factor analysis showed that the six-factor solution has a good fit. This finding is consistent with the studies that examine the BANPS scale's factor structure (Barrett et al. 2013). The findings also indicated that the six factor of Play, Anger, Seek, Care, Fear, and Sadness have a desirable internal reliability. Studying the BANPS's factor structure and patterns of factor loadings, using confirmatory factor analysis, represented similar results to what Barrett et al. (2013) obtained by six-factor solution. All the factor loadings were higher than 0.4 .

Investigating the BANPS scale's reliability using $\alpha$ coefficients, test-retest coefficients, and split-half showed the scale's appropriate reliability. The Play, Anger, Seek, Care, Fear, and Sadness subscale's $\alpha$ coefficients were, respectively, $0.81,0.75,0.75,0.79$, and 0.73 , and the amplitude of test-retest and split-halfs coefficients suggested the BANPS's suitable reliability to measure Play, Anger, Seek, Care, Fear, and Sadness. The findings are consistent with the study of Barrett et al. (2013), who designed the original BANPS. Results indicate acceptable internal consistency, perhaps with some changes in the questionnaire because the results of factor analysis showed that a better questionnaire can be built for other samples.

The validity of the BANPS with the NAPAS (Joshanloo 2017) and Emotion Awareness Questionnaire (Rieffe et al. 2007) showed a positive correlation between the similar subscales of the BANPS with the subscales of NAPAS (Joshanloo 2017) and Emotion Awareness Questionnaire (Rieffe et al. 2007), which were significantly correlated with the last subscale. BANPS showed a positive correlation with the NAPAS (Joshanloo 2017) and Emotion Awareness Questionnaire (Rieffe et al. 2007, Mroczek and Kolarz 1998), and this corre- lation was significant. This result demonstrated the divergent validity of the BANPS.

BANPS's psychometric properties in the present study were respectively consistent with the studies done in the original version (Barrett et al. 2013). According to what was said, the lack of a concise yet valid and useful tool to assess the affective neuroscience is the weakness of the affective neuroscience domain. As a result, it seems that, regardless of language and culture, and considering the pattern of factor loadings, which is similar to previous studies (Barrett et al. 2013), the BANPS scale is a useful tool in measuring the fundamental structures, which is more related to affective neuroscience. But it seems that careful consideration should be given to it in other samples. The psychometric properties of BANPS are applicable broadly and have the capacity to measure affective neuroscience, and can also be used in clinical and normal levels.

The reliability and validity analysis and confirmatory analysis demonstrated the desirable psychometric characteristics of BANPS, and the present study's findings are consistent with the original versions (Barrett et al. 2013). BANPS in normal population samples showed that it is a valid tool for assessing affective neuroscience. The calculated indices to evaluate the fit of the BANPS model suggested that SRMR, RMSEA, and $\left(\mathrm{X}^{2} / \mathrm{df}\right)$ indices are the most valid fit indices (Brown 2006; Schermelleh-Engel et al. 2003; Hair et al. 2009; Hu and Bentler 1999; Tabachnick and Fidell 2007). This result is consistent with the original version of BANPS (Barrett et al. 2013). According to what was said, the present study was conducted among normal samples, and since it did not cover the all groups, the results should be treated with caution in generalising. It is also suggested that future studies examine the validity of BANPS by using other psychological means and clinical groups. The results of the present study indicate that BANPS has acceptable validity and reliability in normal samples. In addition, the questionnaire's factor structure was compliant with the designers' theory, and the five produced factors of the confirmatory factor analysis were consistent with the original version of BANPS.

\section{Reference}

1. Ali A, Toner BB, Stuckless N, et al. Emotional abuse, selfblame, and self-silencing in women with irritable bowel syndrome. Psychosom Med 2000; 62: 76-82.

2. Barrett FS, Robins RW, Janata P. A Brief Form of the Affective Neuroscience Personality Scales. Psychol Assess 2013; 25: 826-843. 
3. Brown TA. Confirmatory factor analysis for applied research. Guilford Press, New York 2006.

4. Corstorphine E. Cognitive-emotional-behavioural therapy for the eating disorders: working with beliefs about emotions. Europ Eat Dis Rev 2006; 14: 448-461.

5. Cramer KM, Gallant MD, Langlois MW. Self-silencing and depression in women and men: Comparative structural equation models. Pers Ind Diff 2005; 39: 581-592.

6. Davis KL, Panksepp J, Normansell L. The Affective Neuroscience Personality Scales: Normative Data and Implications. Neuropsychoanalysis 2003; 5: 57-69.

7. Ehlers A, Clark DM. A cognitive model of posttraumatic stress disorder. Behav Res Ther 2000; 38: 319-345.

8. Gross JJ, Thompson RA. Emotion regulation: Conceptualfoundations. In JJ Gross (ed.), Handbook of emotion regulation (pp. 3-24). Guilford Press, New York 2007.

9. Hair JF, Black WC, Babin BJ, Anderson RE. Multivariate data analysis. Pearson Prentice Hall, New Jersey 2009.

10. Hu LT, Bentler PM. Cutoff criteria for fit indexes in covariance structure analysis: Conventional criteria versus new alternatives. Structural Equation Modeling A: Multidisciplinary Journal 1999; 6: 1-55.

11. Jöreskog KG, Sörbom D. LISREL 8.80 for Windows [ComputerSoftware]. Scientific Software International, Inc, Lincolnwood 2006.

12. Joshanloo M. Factor structure and criterion validity of original and short versions of the Negative and Positive Affect Scale (NAPAS). Personality and Individual Differences 2017; 105: 233-237.

13. Kring A, Sloan D. Emotion regulation and psychopathology. Guilford Press, New York 2010.

14. Kring AM. Emotion disturbances as transdiagnostic processes in psychopathology. In L Lewis, JM HavilandJones, LF Barrett (eds.), Handbook of emotions (3 ${ }^{\text {rd }}$ ed., pp. $691-$ 705). Guilford Press, New York 2008.

15. Mroczek DK, Kolarz CM. The effect of age on positive and negative affect: Adevelopmental perspective on happiness. Journal of Personality and Social Psychology 1998; 75: 1333-1349.

16. Panksepp P. what is an emotional feeling? Lessons about affective origins from cross-species neuroscience. Motiv Emotion 2012; 36: 4-15.

17. Rieffe C, Meerum Terwogt M, Petrides KV, et al. Psychometric properties of the Emotion Awareness Questionnaire forchildren. Personality and Individual Differences 2007; 43: 95-105.

18. Rothbart MK, Ahadi SA, Evans DE. Temperament and personality: origins and outcomes. Journal of Personality and Social Psychology 2000; 78: 122-135.

19. Schermelleh-Engel K, Moosbrugger H, Müller H. Evaluating the fit of structural equation models: Tests of significance and descriptive goodness of fit measures. Psychol Res 2003; 8: 23-74.

20. Surawy C, Hackmann A, Hawton K, Sharpe M. Chronic fatigue syndrome: a cognitive approach. Behav Res Ther 1995; 33: 535-544.

21. Tabachnick BG, Fidell LS. Using multivariate statistics ( $5^{\text {th }}$ ed.). Pearson, Boston 2007

22. Vuilleumier P. How brains beware: neural mechanisms of emotional attention. Trends Cogn Sci 2005; 9: 585-594.

23. Watson D, Clark LA, Harkness AR. Structures of personality and their relevance to psychopathology. Journal of Abnormal Psychology 1994; 103: 18-31.

24. Woolfolk RL, Allen LA. Treating somatization: a cognitivebehavioural approach. Guilford Press, New York 2007. 